\title{
Effect of Wetting-Drying Cycles on Mechanical Behaviour and Electrical Resistivity of Unsaturated Subgrade Soil
}

\author{
Zhi Hu $\left(\mathbb{D}\right.$, Kai Peng, Lihua Li $\mathbb{D}^{D}$, Qiang Ma $\mathbb{D}^{\mathbb{D}}$, Henglin Xiao $\mathbb{D}^{D}$, Zhichao Li, and Pinbo Ai \\ School of Civil Engineering, Architecture and Environment, Hubei University of Technology, Wuhan 430068, China \\ Correspondence should be addressed to Lihua Li; researchmailbox@163.com
}

Received 7 February 2019; Revised 24 April 2019; Accepted 20 May 2019; Published 16 June 2019

Academic Editor: Claudia Vitone

Copyright (c) 2019 Zhi Hu et al. This is an open access article distributed under the Creative Commons Attribution License, which permits unrestricted use, distribution, and reproduction in any medium, provided the original work is properly cited.

\begin{abstract}
Compacted soil is widely used in road and railway subgrade, while alternation of seasons can cause fluctuations in moisture content of soil (i.e., wetting-drying cycles) and influence the performance of soil. In order to research the effect of wetting-drying cycles on mechanical behaviour and electrical resistivity of compacted unsaturated subgrade soil, wetting-drying tests considering different number and cyclic amplitude were conducted on compacted unsaturated clay specimens, and the electrical resistivity and unconfined compressive strength of soil were measured in this study. The AC (alternative current) two-electrode method was applied in the resistivity measurement. The experimental results show that increasing number and cyclic amplitude of wettingdrying cycles can both reduce the strength and electrical resistivity of the compacted unsaturated specimens. After 3-4 wettingdrying cycles, the strength and electrical resistivity tend to be constant value. The change of pore structure can be the key factor leading to the reduction of electrical resistivity of soil subjected to wetting-drying cycles and consequently causing the decrease of soil strength in the present study. Thus, the electrical resistivity can be adopted to indirectly assess the mechanical behaviour of unsaturated compacted soil after wetting-drying cycles.
\end{abstract}

\section{Introduction}

Compacted soil is extensively applied as filling materials in ground treatment of buildings, retaining walls, dams, and especially in road/railway subgrade. Most of the subgrade soil is located in relatively shallow depth, so it can be vulnerable to wetting-drying cycles due to variations of meteorological and hydrological conditions especially in humid subtropical regions [1,2]. A large number of studies have been conducted on the effect of wetting-drying cycles on properties of compacted soil. Most are focused on the mechanical and deformation behaviours [3-7]. It has been discovered that soil strength may decrease after a certain number of wetting-drying cycles. Chen et al. [8] recently investigated the impact of wetting-drying cycles on the shear strength of an unsaturated compacted soil by controlling suction. However, results show that the shear strength has a slight increase after five cycles, which is explained as the densification effect of wetting-drying cycles on soil. For unsaturated soil, suction is an important factor influencing the soil properties. Wetting-drying cycles can be treated as an alternative loading on the soil in form of suction along with the change of moisture content. So, the soil-water characteristic or hydromechanical behaviour is also studied $[1,9,10]$. The initial condition and suction path can affect the properties of soil subjected to cyclic wetting-dryings. Moreover, some investigations have been conducted on the soil structure [11] and microscale behaviour [12].

As an important behaviour of soil, strength for different wetting-drying cycles can hardly be tested and obtained on a single specimen. Because uncovered damage occurs when loading on soil exceeds its strength, further wetting-drying test cannot be carried out on it. Thus, testing of soil strength is performed on different specimens, and this inevitably reduces the reliability of results. To make up for this, methods and indexes of nondestructive testing can be applied to reveal the evolution of soil behaviour synchronously during wetting-drying cycles, including CT (computed tomography) [13], electrical resistivity/conductivity, ultrasonic velocity [14], surface morphology [15], NMR (nuclear magnetic resonance) [16], etc. 
Taking advantage of convenient operation and relative low cost, electrical resistivity is largely used to study the soil behaviour [17-21]. The electrical resistivity of unsaturated soil is primarily determined by material composition, structures, and characteristics of pore fluid in soil [22, 23]. In the process of wetting-drying cycles, electrical resistivity of soil can change apparently, while the change trend and the mechanism are in dispute. The DC (direct current) twoelectrode method was applied to investigate the electrical behaviour of clay, and results show a rise in electrical resistivity with increasing number of wetting-drying cycles $[24,25]$. Recently, Huang et al. [26] reported that the shear strength has a significant drop after wetting-drying paths while the changes of electrical resistivity are not keeping in a consistent trend. In addition, few studies on the effect of cyclic amplitude and the evolution of electrical resistivity during wetting-drying cycles have been reported. Thus, further studies on the electrical properties of compacted unsaturated soil with wetting-drying cycles are needed.

In this paper, the mechanical behaviour and electrical resistivity of compacted unsaturated clay under wettingdrying cycles are studied. The AC (alternative current) two-electrode method was adopted to measure the electrical resistivity of soil, and unconfined compression tests were conducted for each wetting-drying cycle. Then, the effect of number and cyclic amplitude of wetting-drying cycles on soil strength and electrical resistivity is investigated. Finally, the relationship between soil strength and electrical resistivity is discussed.

\section{Experimental Program}

2.1. Tested Material and Specimen Preparation. The soil used in the tests was clay collected from a site in Wuhan, China. The impurities and rocks in soil were firstly removed. Then, the soil samples were sieved through a $2 \mathrm{~mm}$ sieve and airdried. The basic material properties of the soil were investigated in laboratory as listed in Table 1 . The clay was classified as clay of low plasticity (CL) according to the Unified Soil Classification System (USCS).

For cyclic wetting-drying tests, the air-dried soil samples were wetted to optimum moisture content (i.e., $M C=16 \%$ ). After reaching the design moisture content, the wet soil samples were kept in a sealed plastic bag for at least 24 hours. Then cylindrical specimens $(38 \mathrm{~mm}$ in diameter and $76 \mathrm{~mm}$ high) were prepared referring to the procedures of tamping method described in ASTM standard D5311. Five layers were used in the compaction, and the height was used to determine the degree of compaction for each layer. A top cap was placed on the last layer, and continuous compression on the top cap was applied until the desired dry density was obtained. In this study, the dry density of specimens was controlled as $\rho_{\mathrm{d}}=1.84 \mathrm{~g} / \mathrm{cm}^{3}$, which corresponds to degree of compaction $K=0.93$, the compaction criteria of heavyhaul railway subgrade (Chinese code of design of heavy-haul railway, TB 10625-2017). Then, all specimens were wrapped with plastic films and cured in a desiccator for 24 hours, to accelerate uniform distribution of moisture in the specimens. In order to study the effects of dry density and
TABLE 1: Basic material properties of the tested clay.

\begin{tabular}{lc}
\hline Property & Value \\
\hline Grain composition (\%) & \\
$>0.075 \mathrm{~mm}$ & 16.1 \\
0.075 to $0.05 \mathrm{~mm}$ & 4.8 \\
0.05 to $0.01 \mathrm{~mm}$ & 36.3 \\
0.01 to $0.005 \mathrm{~mm}$ & 8.4 \\
0.005 to $0.002 \mathrm{~mm}$ & 9.4 \\
$<0.002 \mathrm{~mm}$ & 20.2 \\
Specific gravity, $G_{\mathrm{s}}$ & 2.76 \\
Liquid limit, LL $(\%)$ & 37.0 \\
Plastic limit, PL $(\%)$ & 20.0 \\
Plastic index, PI $(\%)$ & 17.0 \\
Maximum dry density, $\rho_{\mathrm{dmax}}\left(\mathrm{g} / \mathrm{cm}^{3}\right)$ & 1.98 \\
Optimum moisture content, OMC $(\%)$ & 16.0 \\
Saturated moisture content $(\%)$ & 25.5 \\
\hline
\end{tabular}

moisture content on the electrical resistivity, specimens with various dry densities $\left(1.68 \mathrm{~g} / \mathrm{cm}^{3}, 1.78 \mathrm{~g} / \mathrm{cm}^{3}, 1.84 \mathrm{~g} / \mathrm{cm}^{3}\right.$, and $\left.1.88 \mathrm{~g} / \mathrm{cm}^{3}\right)$ and moisture contents $(10 \%, 12 \%, 14 \%, 16 \%$, $18 \%$, and $20 \%$ ) were prepared. The same procedure of preparation and processing was applied as described above. Here, the dry density $\rho_{\mathrm{d}}=1.68 \mathrm{~g} / \mathrm{cm}^{3}, 1.78 \mathrm{~g} / \mathrm{cm}^{3}, 1.84 \mathrm{~g} / \mathrm{cm}^{3}$, and $1.88 \mathrm{~g} / \mathrm{cm}^{3}$ corresponds to degree of compaction $K=0.85,0.90,0.93$, and 0.95 , respectively.

\subsection{Test Equipment and Procedures}

2.2.1. Cyclic Wetting-Dying Test. Cyclic wetting-drying tests were performed following the procedures in the authors' previous study [27]. Specimens were wetted by a spray bottle and dried by air. The moisture content of the specimens was controlled by controlling the mass of the specimen. Initial moisture content and initial mass of specimen can be measured first, and equation (1) was applied to control the target mass of the specimen:

$$
m_{1}=\frac{w_{1}}{1+w_{0}} m_{0}
$$

where $m_{0}$ and $m_{1}$ are initial mass and target mass of specimen and $w_{0}$ and $w_{1}$ represent initial and target moisture content of the specimen.

For compacted subgrade, the soil is typically compacted at optimum moisture content (OMC). After several alternations of seasons, the moisture content in subgrade soil may increase slightly to a so-called equilibrium moisture content (EMC) [28]. Moreover, concerning long-term service of road or railroad, the moisture content of subgrade soil shows periodic fluctuation around the equilibrium moisture content. Based on the phenomenon, the wettingdrying path in the present study was designed as illustrated in Figure 1. The specimens were prepared at OMC as described above firstly and then wetted to EMC to start the wetting-drying cycles. When reaching the desired number of wetting-drying, the moisture content of specimens was kept at EMC for further testing. The EMC was set as $17 \%$ in the test, and the cyclic amplitude of wetting-drying was considered as $\mathrm{EMC} \pm 1 \%, \mathrm{EMC} \pm 3 \%$, and $\mathrm{EMC} \pm 5 \%$. Since 


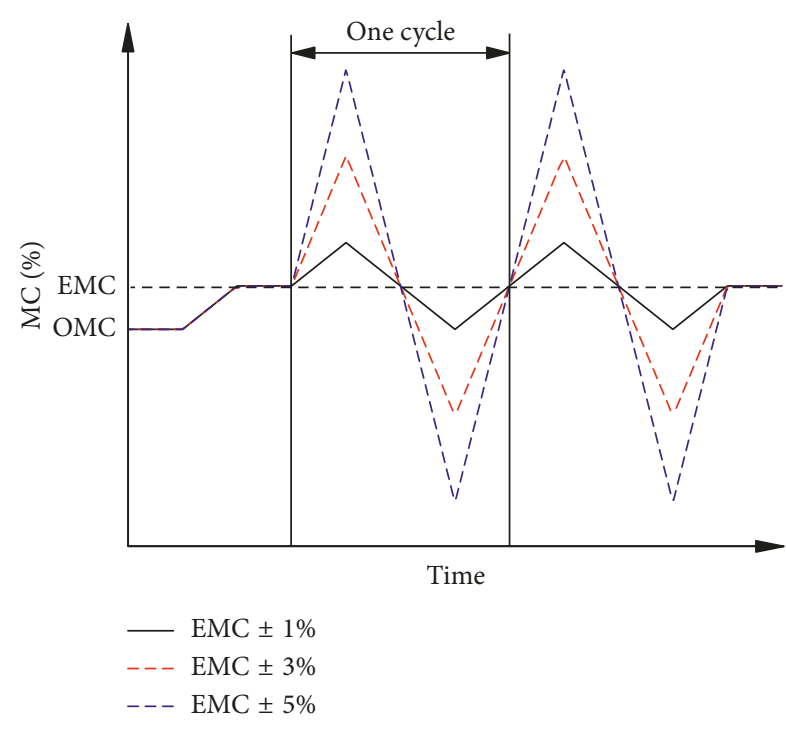

FIGURE 1: Wetting-drying path.

many studies $[10,15,29,30]$ have reported that the influence of wetting-drying cycles on the properties of soil is limited after 4 to 6 cycles, the maximum number of wetting-dryings was selected as five cycles in this study. After each wettingdrying cycle, the dimensions of the specimen should be measured to calculate volumetric strain of specimens. A vernier caliper with an accuracy of $0.01 \mathrm{~mm}$ was applied to measure diameters and height of the specimen. To calculate the volumetric strain, the volume change of the specimen compared with initial volume was divided by initial volume. Moreover, unconfined compression tests should be conducted on each layer.

2.2.2. Electrical Resistivity Measurement. For laboratory electrical resistivity measurement of soil, the four-electrode method and two-electrode method can be used [24, 31]. The devices of two-electrode method are simple, while contact resistance between electrode and soil is usually large especially at low moisture content. The contact resistance can be neglected when using four-electrode method, but soil specimen could be disturbed by the insertion of two measuring electrodes. Since soil strength should be obtained after wetting-drying cycles, the two-electrode method was selected in this study to keep the integrality of specimens. Moreover, an alternative current (AC) supply was used rather than direct current (DC) supply, to avoid polarization of soil and electrode. The schematic of electrical resistivity measurement is shown in Figure 2. Note that $\mathrm{Hc}$ and Lc represent high and low currents and $\mathrm{Hp}$ and Lp represent high and low potentials. For the sake of reducing contact resistance, a fixed-weight block was applied on the top platen during the measurement. The weight of block can be adjusted for different experimental conditions. Within an independent study or a set of tests, the weight should be fixed to ensure comparability of data.

A LCR digital bridge (TH2817A, Tonghui Electronic Co., Ltd) was adopted to measure the electrical resistance of soil specimens, as shown in Figure 3. Meanwhile, the diameter

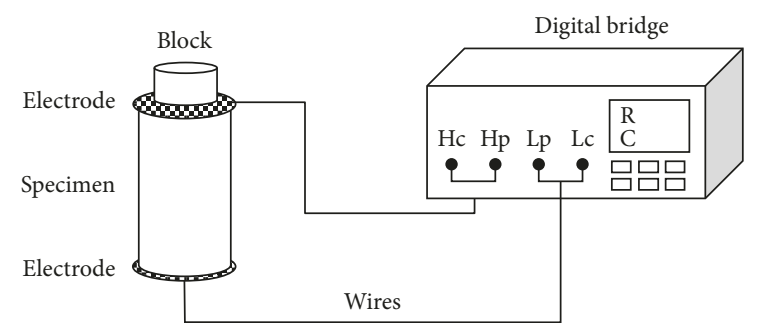

FIgURE 2: Schematic of electrical resistivity measurement.

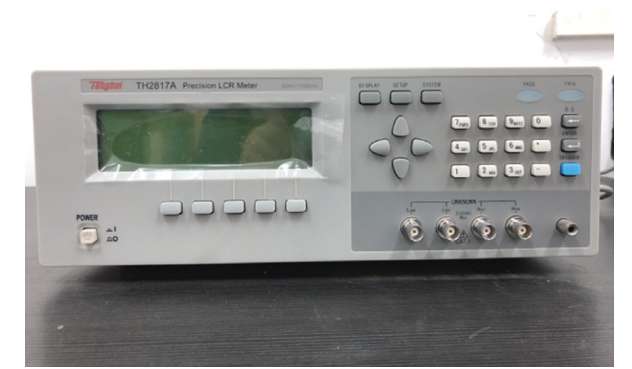

Figure 3: The digital bridge (Tonghui, TH2817A).

$(D)$ and length of specimen $(L)$ were measured carefully to calculate the electrical resistivity of specimen applying the following equation:

$$
\rho=\frac{R A}{L},
$$

where $\rho$ is electrical resistivity, $R$ is electrical resistance, $A$ is the cross section area calculated by the diameter $D$ of specimen, and $L$ is the length of the specimen.

When using AC power supply, the AC frequency has a dramatic effect on the electrical resistivity of soil. The electrical resistivity of three specimens with different moisture contents $(\mathrm{MC}=12 \%, 17 \%$, and $22 \%)$ is presented in Figure 4, considering a sequence of current frequencies $(100 \mathrm{~Hz}, 500 \mathrm{~Hz}, 1 \mathrm{kHz}, 5 \mathrm{kHz}, 10 \mathrm{kHz}, 20 \mathrm{kHz}$, and $50 \mathrm{kHz})$. It can be seen that the electrical resistivity decreases sharply when the current frequency varies from $100 \mathrm{~Hz}$ to $1 \mathrm{kHz}$. When the current frequency exceeds $10 \mathrm{kHz}$, the measured electrical resistivity tends to be constant. Besides, the data volatility is gradually reduced as the current frequency increases. It can be also observed from the figure that the specimen with low moisture content is more sensitive to current frequency. Rinaldi and Cuestas [32] have reported that electrode polarization occurs below $2 \mathrm{kHz}$ or $3 \mathrm{kHz}$ and double layer relaxation appears beyond $100 \mathrm{kHz}$. The conductivity of soil exhibits almost constant behaviour between the above mentioned frequencies, namely, ohmic conduction. In order to avoid electrode polarization and improve data stability, current frequency was chosen as $50 \mathrm{kHz}$ in this study, and the measuring voltage was fixed at default value of the equipment, i.e., $1 \mathrm{~V}$.

It is known that the electrical resistance is very sensitive to temperature; thus, a temperature correction of electrical resistivity is necessary. For this purpose, three specimens were used to record the electrical resistivity at different temperatures. Results are shown in Figure 5. By applying the 


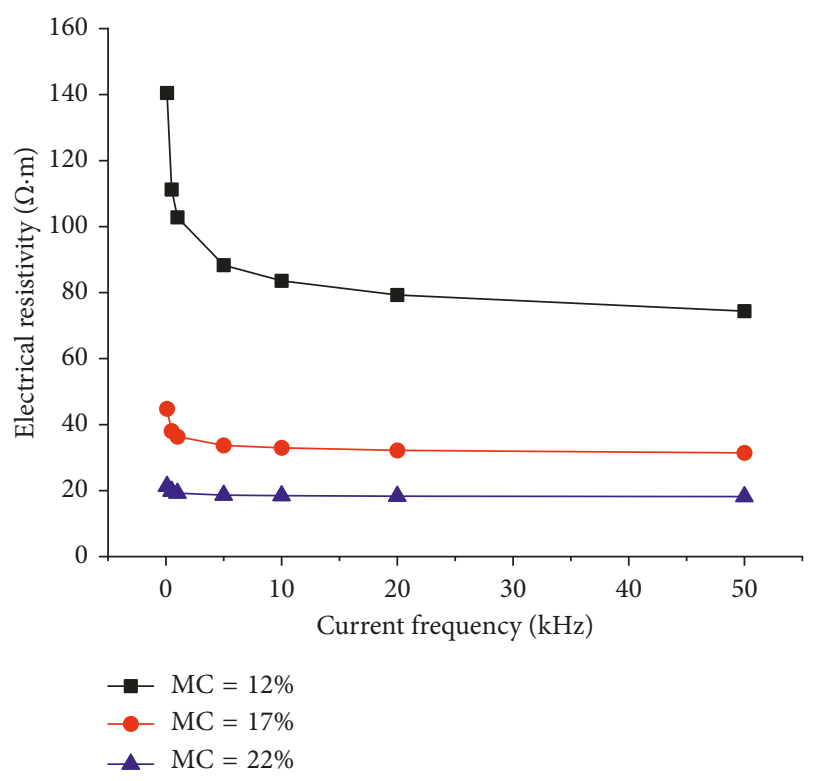

FIGURE 4: Variations of electrical resistivity with different current frequencies.

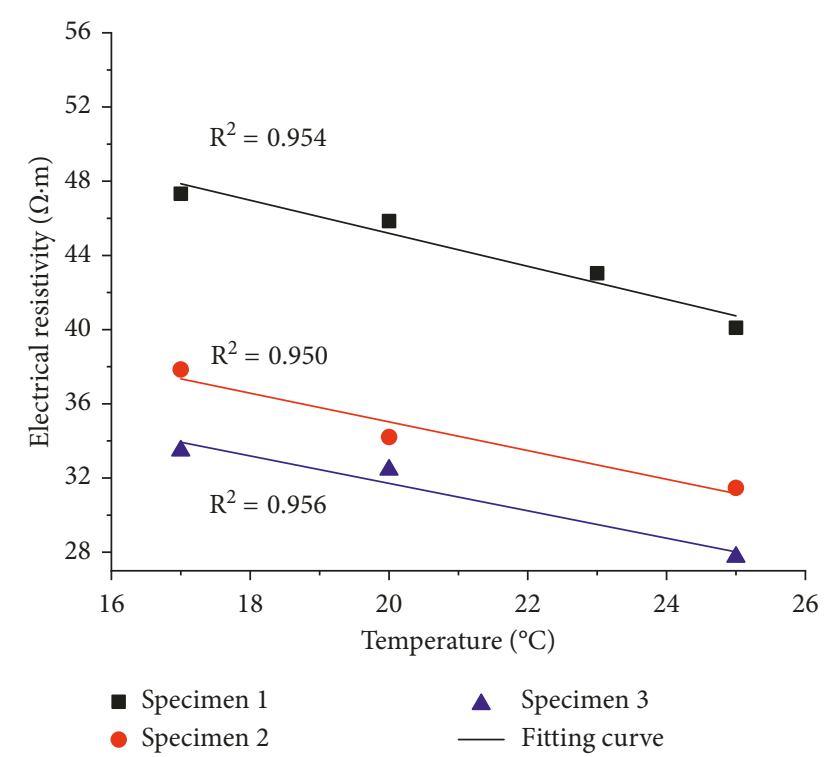

Figure 5: Temperature correction curves for electrical resistivity.

temperature correction equation as shown in equation (3), the relationship between electrical resistivity at any temperature and electrical resistivity at $25^{\circ} \mathrm{C}$ can be calculated [24]:

$$
\rho_{25}=\rho_{T}[1+\alpha(T-25)],
$$

where $\rho_{25}$ is electrical resistivity at $25^{\circ} \mathrm{C}, \rho_{T}$ is electrical resistivity at temperature $T, T$ is the test temperature, and $\alpha$ is the empirical correction coefficient.

One can obtain the average correction coefficient $\alpha=0.0205^{\circ} \mathrm{C}^{-1}$. Temperatures during measurement are all recorded to convert the electrical resistivity into values at temperature $T=25^{\circ} \mathrm{C}$. The electrical resistivity of specimens was measured at each wetting-drying cycle and before the unconfined compression test.

2.2.3. Unconfined Compression Test. After the specimens underwent cyclic wetting-drying, unconfined compression tests were conducted on these specimens. The test procedures were following the method described in ASTM standard D2166/D2166M. A strain-controlled compression apparatus was used as shown in Figure 6. The strain rate was controlled at $2 \% / \mathrm{min}$. Note that for unsaturated clay, matric suction can be a significant influencing factor on soil strength. In this study, with careful preparation of specimens, the differences of initial dry unit weight and initial moisture content were very small between each specimen. As known, matric suction is determined by degree of saturation at a constant dry unit weight. Here, the specimens have nearly the same dry unit weight and degree of saturation, so we consider the initial matric suctions of specimens are the same.

\section{Results and Discussions}

3.1. Effect of Dry Density and Moisture Content on Soil Electrical Resistivity. The electrical resistivity of compacted clay with different dry densities and moisture contents is presented in Figure 7. As shown in the figure, the electrical resistivity of soil with the same dry density is obviously decreased when the moisture content increases. Also, for soil specimens with the same moisture content, higher dry density can cause smaller electrical resistivity. These results are in accordance with previous studies [25] as presented in Figure 7, and it can be proved that the testing method of soil electrical resistivity in this study is reliable. Figure 8 presents the variation of electrical resistivity with degree of saturation. It can be seen that the electrical resistivity decreases as the degree of saturation increases.

3.2. Effect of Wetting-Drying Cycles on Soil Strength. Before the unconfined compression tests, the moisture content of specimens was controlled the same, i.e., $\mathrm{MC}=\mathrm{EMC}$. The actual degree of saturation $\left(S_{\mathrm{r}}\right)$ data of specimens used in unconfined compression tests are presented in Table 2 . It can be seen that $S_{\mathrm{r}}$ falls in the range of $84.4 \%$ to $86.7 \%$ for different specimens. It is known that the suction of soil changes slightly due to variations of degree of saturation in high moisture content conditions [33]; thus, it can be assumed that differences of suction between specimens were very limited, and the effect of suction on soil strength can be neglected at equilibrium moisture content.

The effect of number and cyclic amplitude of wettingdrying cycles on unconfined compressive strength (UCS) of soil is shown in Figure 9. It can be seen that the soil strength reduces with larger number of wetting-drying, and after 3-4 cycles, the soil strength tends to be constant. Additionally, greater reduction in soil strength can be observed with larger cyclic amplitude of wetting-drying. After the 5th wettingdrying cycles, the soil strength can be decreased by $19 \%$, $20 \%$, and $56 \%$ compared to that of noncycle specimen for 


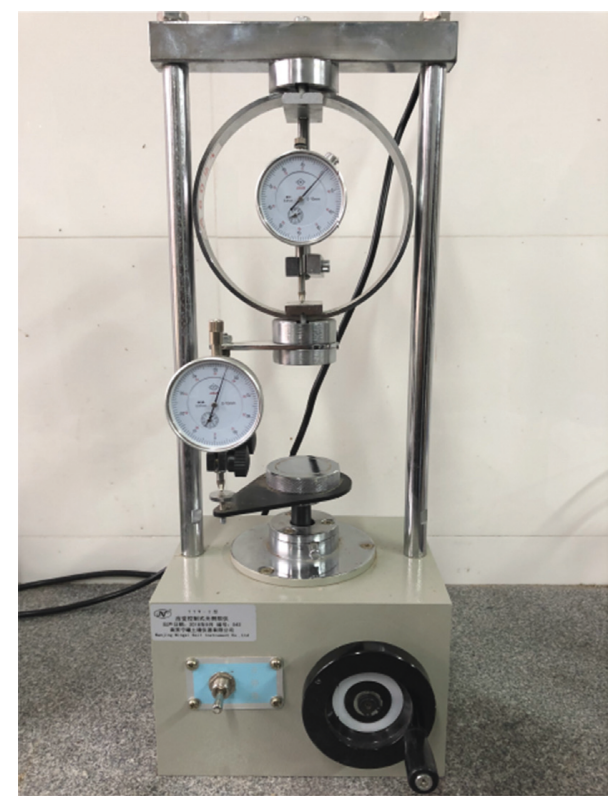

FIGURE 6: The compression apparatus for unconfined compression tests.

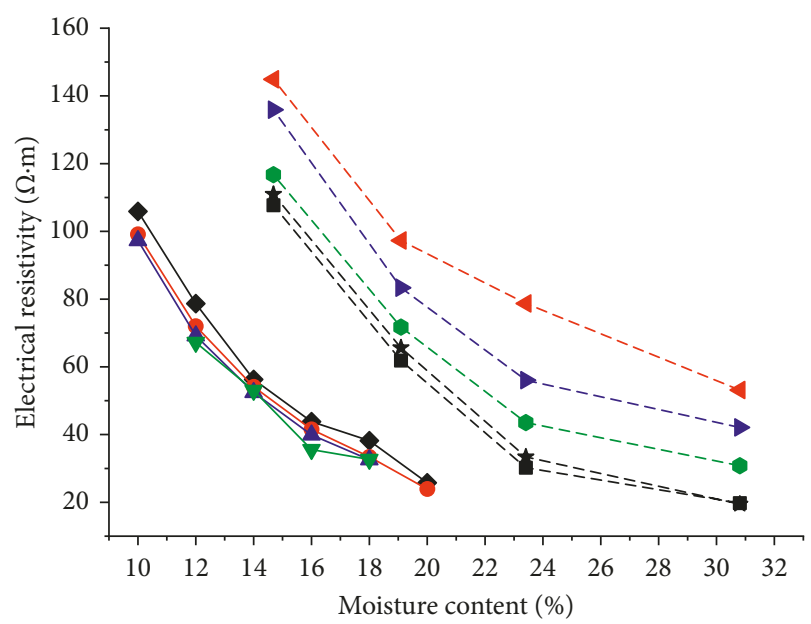

$$
\begin{array}{ll}
\text { Bai et al. [25] } & \text { Present study } \\
-\triangleleft-\rho_{\mathrm{d}}=1.30 \mathrm{~g} / \mathrm{cm}^{3} & -\rho_{\mathrm{d}}=1.68 \mathrm{~g} / \mathrm{cm}^{3} \\
-\rho_{\mathrm{d}}=1.38 \mathrm{~g} / \mathrm{cm}^{3} & -\rho_{\mathrm{d}}=1.78 \mathrm{~g} / \mathrm{cm}^{3} \\
-\rho_{\mathrm{d}}=1.46 \mathrm{~g} / \mathrm{cm}^{3} & -\rho_{\mathrm{d}}=1.84 \mathrm{~g} / \mathrm{cm}^{3} \\
-\rho_{\mathrm{d}}=1.54 \mathrm{~g} / \mathrm{cm}^{3} & \rightarrow-\rho_{\mathrm{d}}=1.88 \mathrm{~g} / \mathrm{cm}^{3} \\
-\rho_{\mathrm{d}}=1.58 \mathrm{~g} / \mathrm{cm}^{3} &
\end{array}
$$

FIGURE 7: Variations of electrical resistivity with moisture content and degree of compaction.

cyclic amplitude of EMC $\pm 1 \%, \mathrm{EMC} \pm 3 \%$, and $\mathrm{EMC} \pm 5 \%$, respectively.

Furthermore, typical photos of specimens after failure undergoing five cycles are presented in Figure 10. With larger cyclic amplitude of wetting-drying, more cracks can be found on the surface of specimen after failure and the width of cracks increases apparently. From the point of view of damage mechanics, the growth and development of macrocracks are related to properties of microcracks and

\begin{tabular}{|c|c|c|c|}
\hline \multirow{2}{*}{$\begin{array}{l}\text { Number of wetting-drying } \\
\text { cycles }\end{array}$} & \multicolumn{3}{|c|}{ Degree of saturation, $S_{\mathrm{r}}(\%)$} \\
\hline & $\mathrm{EMC} \pm 1 \%$ & $\mathrm{EMC} \pm 3 \%$ & $\mathrm{EMC} \pm 5 \%$ \\
\hline 1 & 84.8 & 86.4 & 84.4 \\
\hline 2 & 86.0 & 86.6 & 86.0 \\
\hline 3 & 86.8 & 85.7 & 85.1 \\
\hline 4 & 86.6 & 85.1 & 84.9 \\
\hline 5 & 85.3 & 85.9 & 84.4 \\
\hline
\end{tabular}
material structure change [34]. For unsaturated clay, cracks

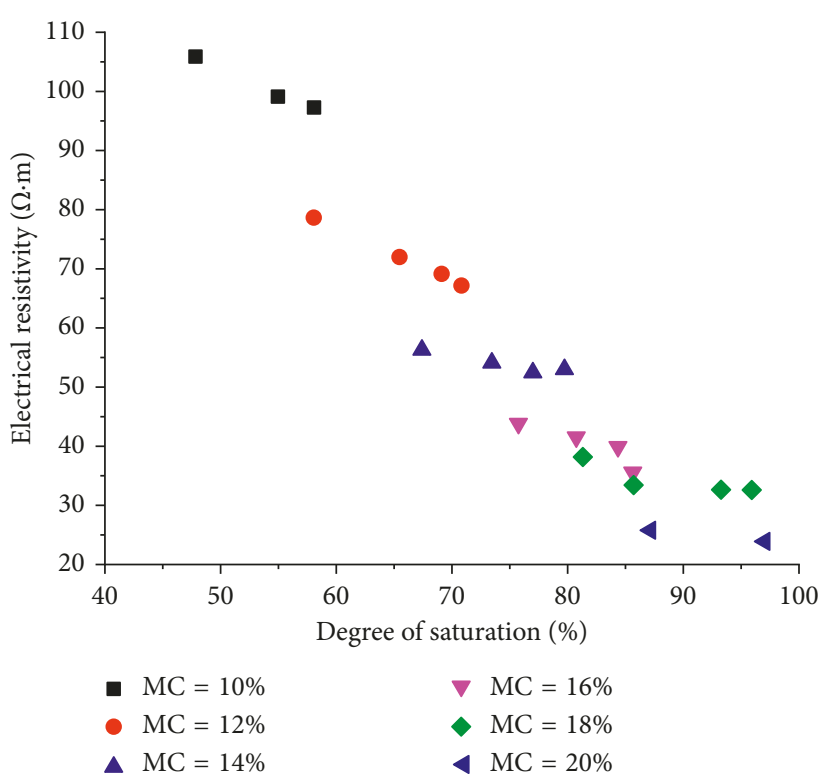

Figure 8: Variations of electrical resistivity with degree of saturation.

TABle 2: Actual degree of saturation of specimens at EMC.

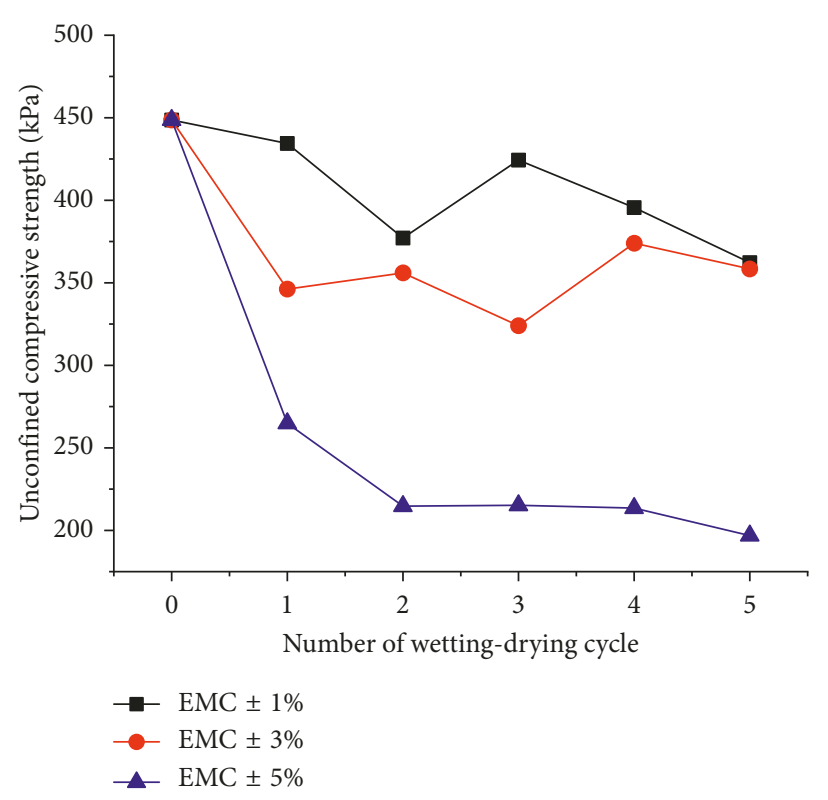

FIGURE 9: Effect of wetting-drying cycles on unconfined compressive strength of soil.

occur when the tensile stress induced by the developed suction exceeds the tensile strength of the specimen during drying path. Some cracks can be repaired in wetting path. 


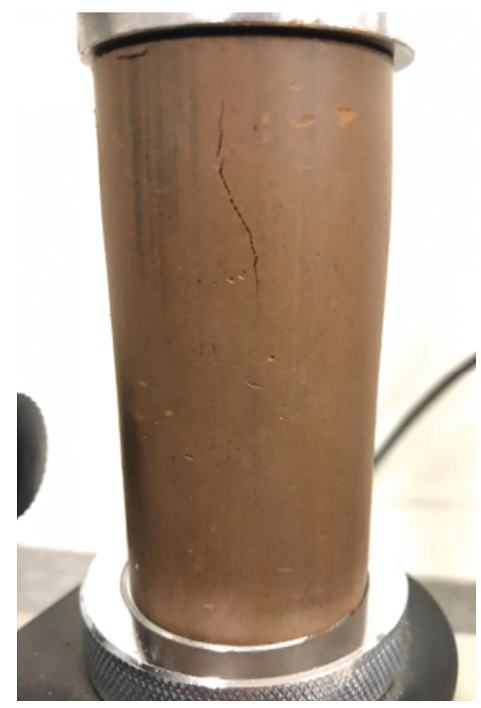

(a)

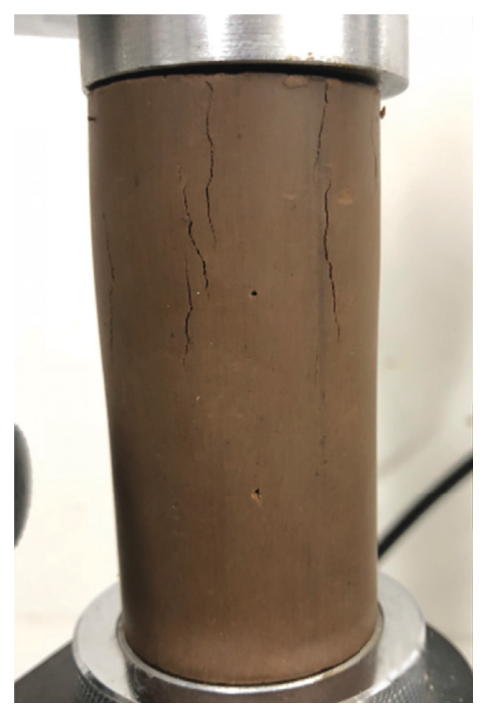

(b)

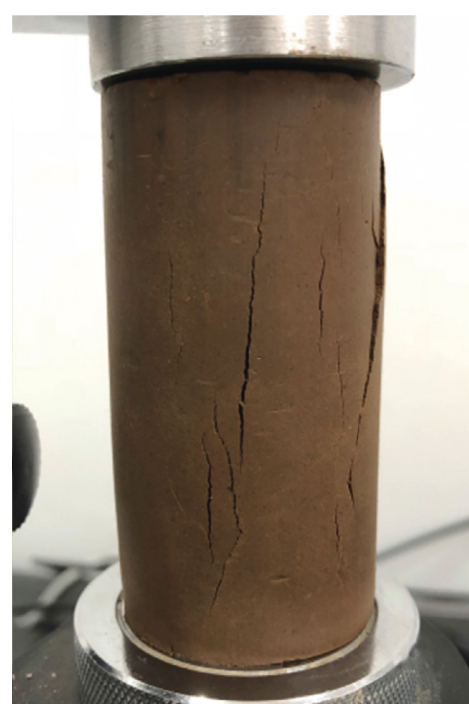

(c)

FIgURE 10: Photos of specimens after failure undergoing five wetting-drying cycles: (a) cyclic amplitude EMC $\pm 1 \%$; (b) cyclic amplitude $\mathrm{EMC} \pm 3 \%$; (c) cyclic amplitude EMC $\pm 5 \%$.

However, irreversible soil structure change can result in accumulation of cracks after wetting-drying cycles [15]. Larger suction range suggests more crack accumulation. Thus, it can be deduced that more microcracks are caused by wetting-drying cycles with larger cyclic amplitude. If the degradation of soil strength is treated as a result of soil damage, the process of soil damage can be the evolution of microcracks and soil structure. It can be also suggested that large fluctuation of soil moisture content could generate significant decline of soil strength. Thus, waterproof and drainage facilities in compacted soil structures appear very important, and more attentions should be paid on the design and construction of hydraulic buffer or hydraulic barrier to reduce fluctuation of moisture content in soil.

\subsection{Effect of Cyclic Wetting-Drying on Soil Electrical} Resistivity. The influences of cyclic wetting-dryings on soil electrical resistivity are presented in Figures 11 and 12. Here, soil moisture content of specimens at the start point is $\mathrm{EMC}=17 \%$. It can be seen from Figure 11 that in each cycle, the soil electrical resistivity firstly decreases, then increases to a peak value, and finally drops to around the initial value. The variations of electrical resistivity are in negative correlation with moisture content. In addition, the soil electrical resistivity shows a fluctuant downward trend with more wetting-drying cycles. Moreover, the higher fluctuation of electrical resistivity can be recognized on specimens subjected to larger cyclic amplitude. It can be also observed that electrical resistivity at maximum moisture content shows a declining trend within the first three wetting-drying cycles. After the 3rd cycle, the electrical resistivity at maximum moisture content becomes stable, while the impact of wetting-drying cycles on the electrical resistivity at minimum moisture content is very small.

For better comparison of electrical resistivity for each wetting-drying cycle, electrical resistivity at moisture

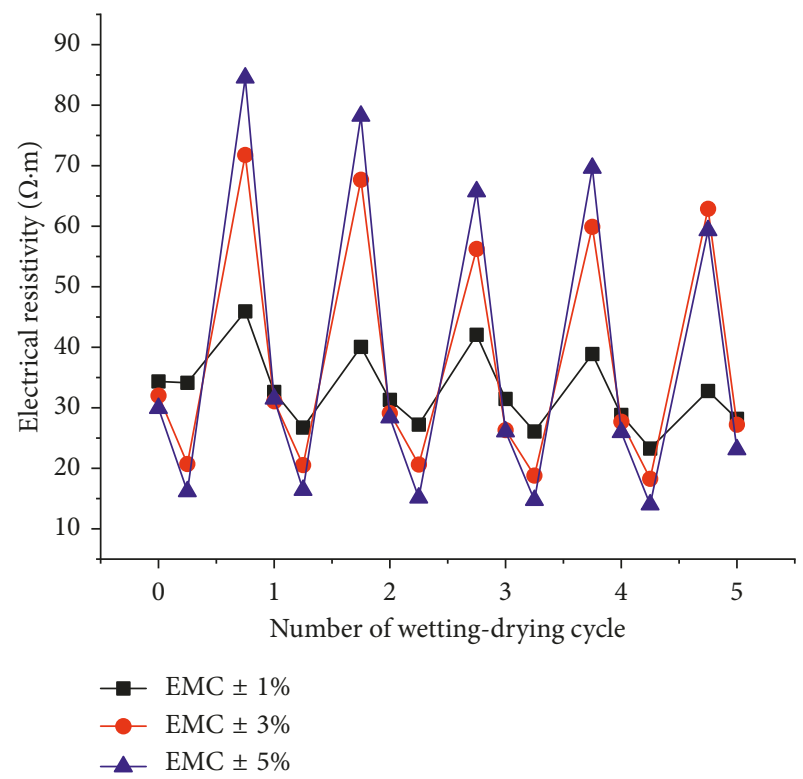

FIgURE 11: Evolutions of soil electrical resistivity with wettingdrying cycles.

content $17 \%$ (i.e., the end point) for each cycle is plotted in Figure 12. Overall, the electrical resistivity of soil decreases rapidly at the first three cycles and becomes a constant value after 3-4 cycles except the cyclic amplitude $\mathrm{EMC} \pm 5 \%$. The increase of cyclic amplitude contributes to the reduction of electrical resistivity, especially after three wetting-drying cycles. It can be suggested from the above results that the electrical resistivity of compacted soil can be greatly reduced by wetting-drying cycles.

Figures 13 and 14 illustrate variations of void ratio and degree of saturation during wetting-drying cycles. In the figures, numbers of wetting-drying cycle and the approximate equilibrium position are indicated. From Figure 13, it can be found that as the number of wetting-drying cycle 


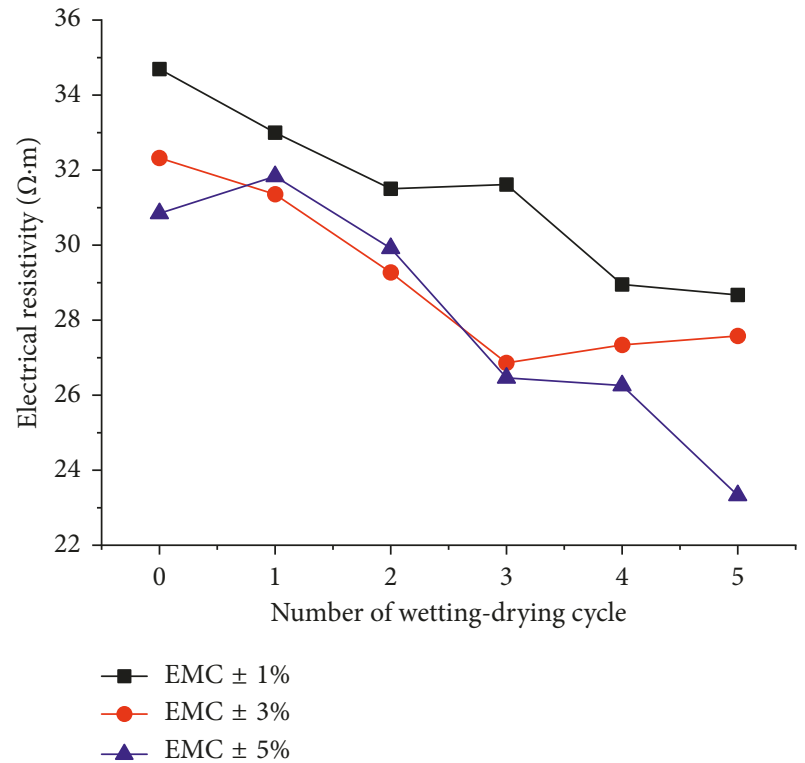

FIgURE 12: Variations of final electrical resistivity with wettingdrying cycles.

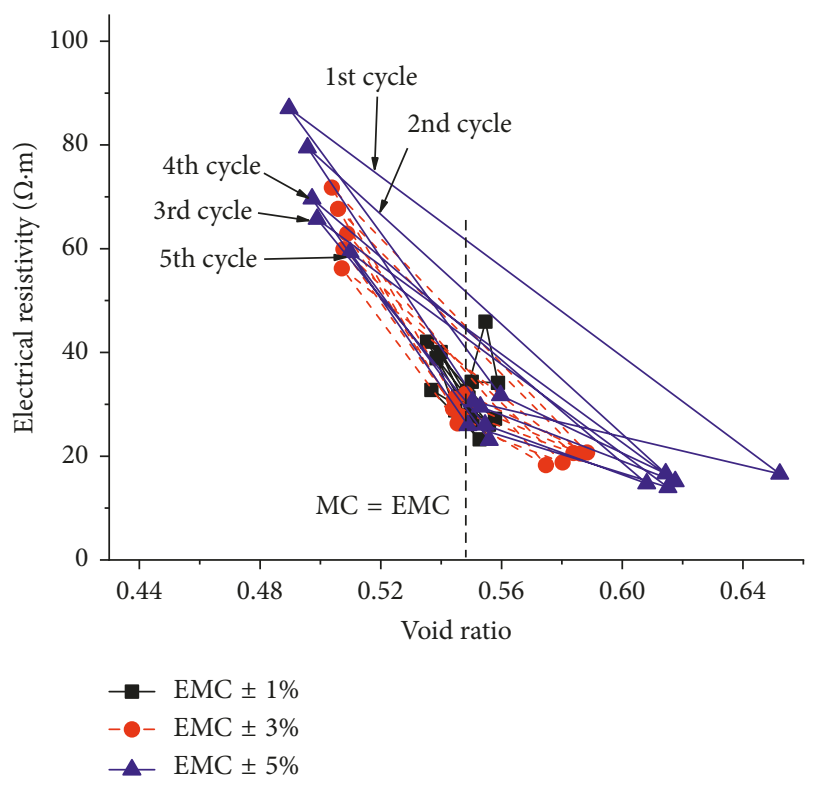

FIGURE 13: Relationship between void ratio and electrical resistivity during wetting-drying cycles.

increases, electrical resistivity shows hysteresis loop against void ratio. For the case of EMC $\pm 5 \%$, the size of hysteresis loop reduces obviously with a movement to the negative axis of the coordinate. Moreover, the first wetting-drying cycle has the major impact on the size reduction of hysteresis loop, and the effect of the rest four cycles is relatively small. This phenomenon is possibly due to that the evolution of soil structure tends to be stable. When cyclic amplitude of wetting-drying reduces from $\mathrm{EMC} \pm 5 \%$ to $\mathrm{EMC} \pm 1 \%$, the hysteresis loop gradually shrinks and disappears. It can be deduced that the cyclic amplitude has great influence on the wetting-drying effect.

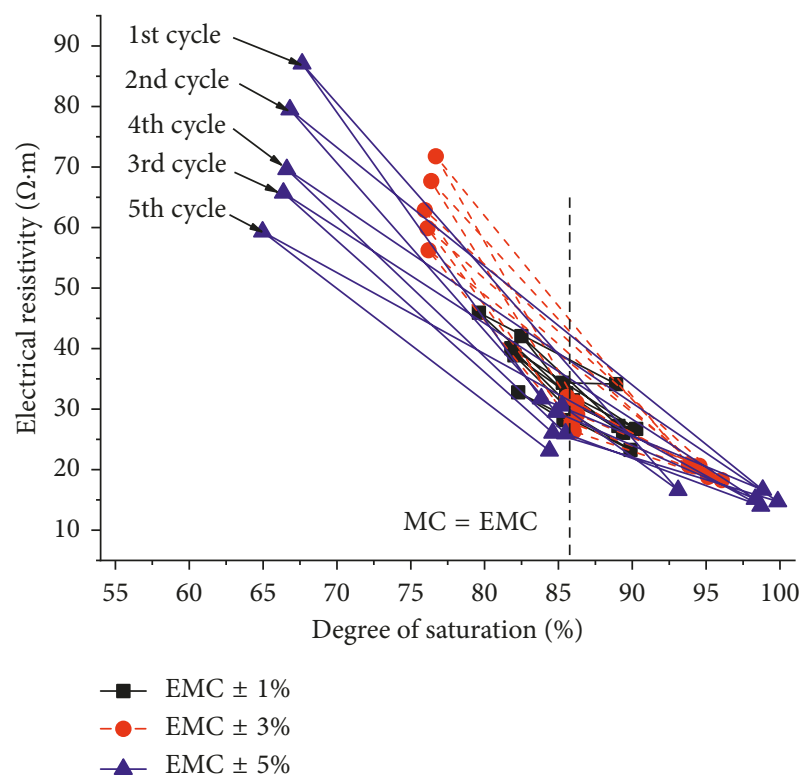

FIGURE 14: Relationship between degree of saturation and electrical resistivity during wetting-drying cycles.

For degree of saturation, similar hysteresis phenomenon can be observed from Figure 14. While the size of hysteresis loop nearly remains the same, the position continuously moves towards low electricity resistivity position. This can be related to the hysteresis effect of water retention characteristics of clay. It can be also obtained that at the equilibrium position, the influences of wetting-drying cycles on void ratio and degree of saturation are tiny.

In this study, all compacted soil specimens are unsaturated during the whole test procedures. The resistivity of unsaturated soil is dominated by porosity, pore structure, degree of saturation, properties of pore fluid, diffuse double layer of clay, temperature, and other factors [22, 23]. For specimens with moisture content of $17 \%$ undergoing different wetting-drying cycles, the changes of degree of saturation and pore fluid can be neglected. Besides, the effect of temperature on electrical resistivity can be ignored due to the temperature correction.

Consequently, the evolution of volumetric strain and apparent density of specimens with wetting-drying cycles are plotted in Figures 15 and 16, respectively. It can be observed from Figure 15 that the volumetric strain of specimens $\mathrm{EMC} \pm 5 \%$ and $\mathrm{EMC} \pm 3 \%$ shows slight swelling, while specimen EMC $\pm 1 \%$ can be considered slightly shrinking. Larger cyclic amplitude of wetting-drying allows the clay larger suction range history. More aggregates and micropores were generated during the wetting-drying cycle, which causes the slight swelling. But overall, volumetric strain and the change of density of specimens are very small. In other words, the influence of porosity change on electrical resistivity is very limited for each end of wetting-drying cycle. This is in accordance with results shown in Figure 13.

Based on electrical model for unsaturated soil proposed by Rhoades et al. [35], there are three electrical conductance elements in unsaturated soil, namely, solid element, liquid element, and solid-liquid series-coupled element, as shown 


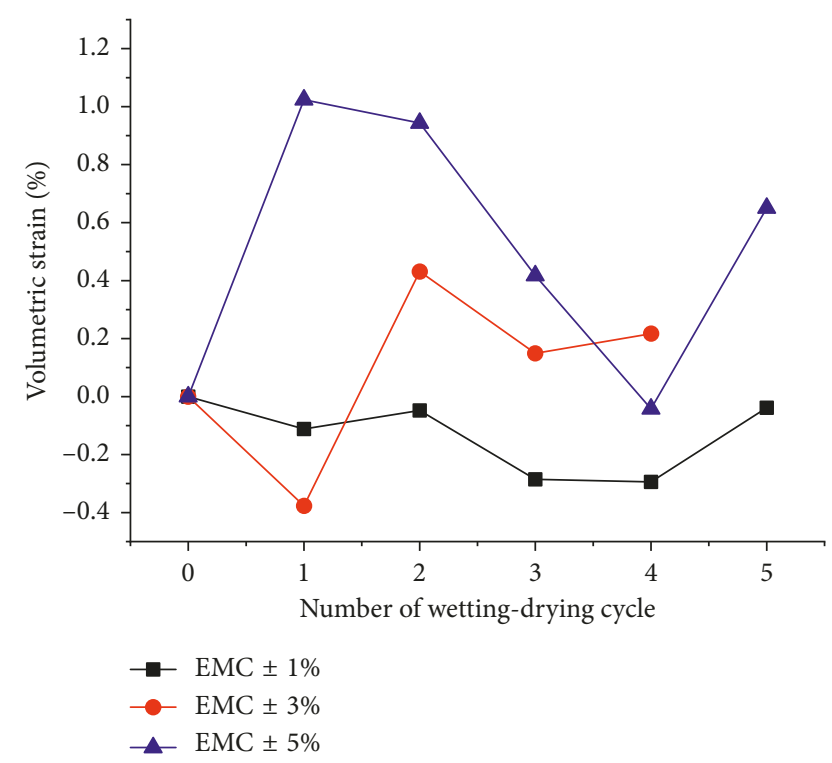

FIGURE 15: Variations of volumetric strain with wetting-drying cycles.

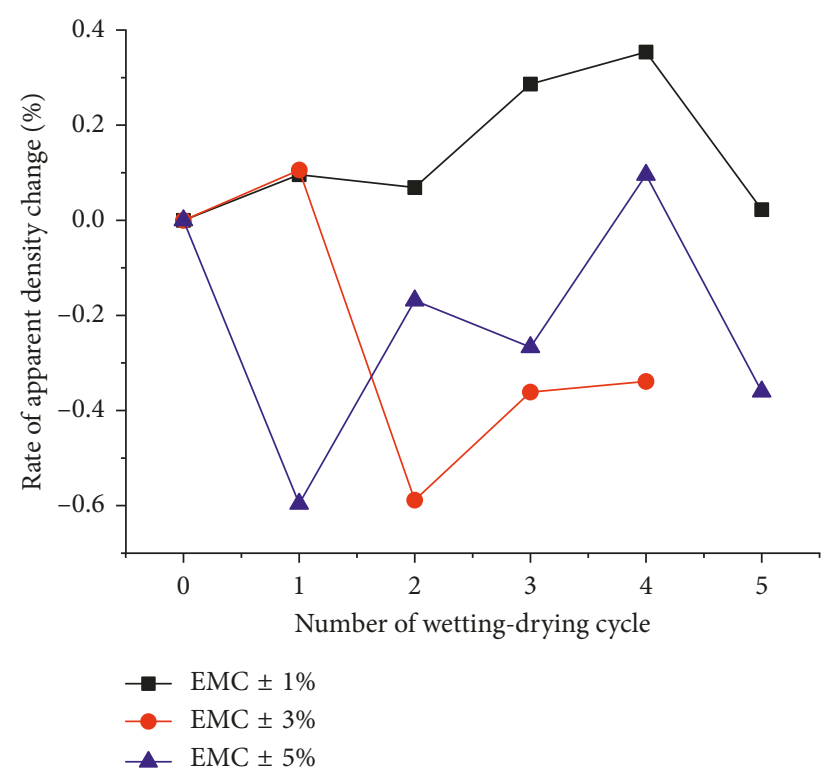

FIGURE 16: Variations of rate of apparent density change with wetting-drying cycles.

in Figure 17. The contribution of solid element is limited as a result of very low conductivity of clay mineral [22]. The liquid element can be also divided into water in diffuse double layer and water in pores or free water. The effect of diffuse double layer mainly depends on characteristics of bulk solution in soil and proportion of clay particle [36]. By ignoring the solution of clay particle, the concentration of bulk solution in soil may keep constant as the same moisture content at the end of each wetting-drying cycle. In addition, proportion of clay particle can be treated a constant value without any pressure on soil. So, it can be deduced that the diffuse double layer would appear to have relatively little role to play on electrical resistivity. As known that the
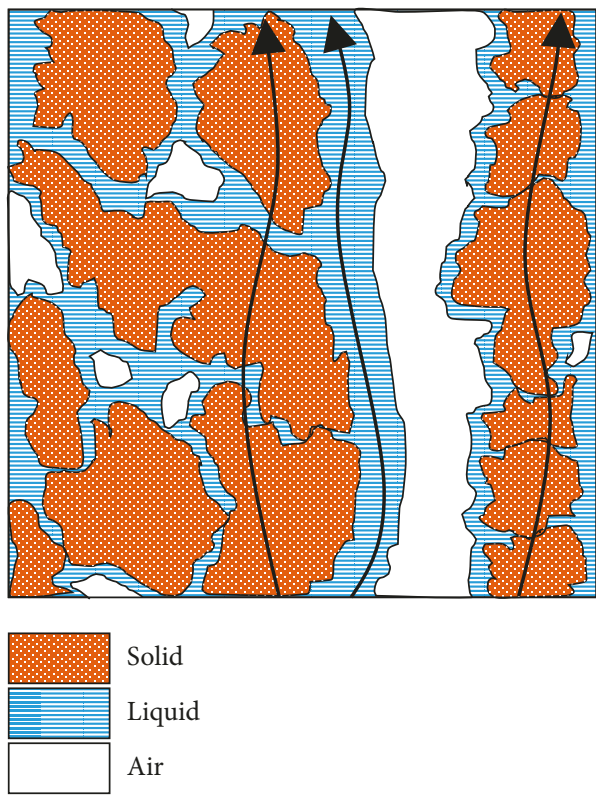

Figure 17: Schematic illustration of three electrical conductance elements in unsaturated soil: (a) solid-liquid series-coupled element, (b) liquid element, and (c) solid element.

conductivity of pore fluid is far larger than soil particle, the increase of fluid element can reduce the electrical resistivity. In other words, it can be achieved mainly by improving the connectivity of pore fluid. Under the premise of constant moisture content, volume, and porosity, the variation of pore structure may improve the connectivity of pore fluid. Hence, the pore structure can be the most likely factor affecting the electrical resistivity during wetting-drying cycles. Bodner et al. [11] have reported that cyclic wetting-drying can decrease the pore range and increase pore size, where the properties of tested soil are similar to this study. Moreover, Ma et al. [37] also found that proportion of large-sized pores is increased after wetting-drying cycles for Quaternary red clay. As discussed above, surface cracks can be observed on the specimens after failure shown in Figure 10, and similar deduction can be obtained that wetting-drying cycles can produce more macropores or cracks in clay due to increasing large-sized pores. Increasing large size pores and decreasing small size pores may lead to pore fluid transporting from small pores to large pores. Here, it can be also deduced that the proportion of fluid element is increased under the condition of constant porosity. Thus, the electrical resistivity of soil reduces as shown in Figure 12. It should be noted that larger cyclic amplitude of wetting-drying has greater impact on the pore structure of soil and consequently causes more reduction in electrical resistivity.

3.4. Relationship between Soil Strength and Electrical Resistivity. The relationship between electrical resistivity and unconfined compressive strength of soil is presented in Figure 18. The unconfined compressive strength shows a linear growth with the increasing electrical resistivity for constant cyclic amplitude of wetting-drying cycles. In the last section, it has been discussed that the reduction of 


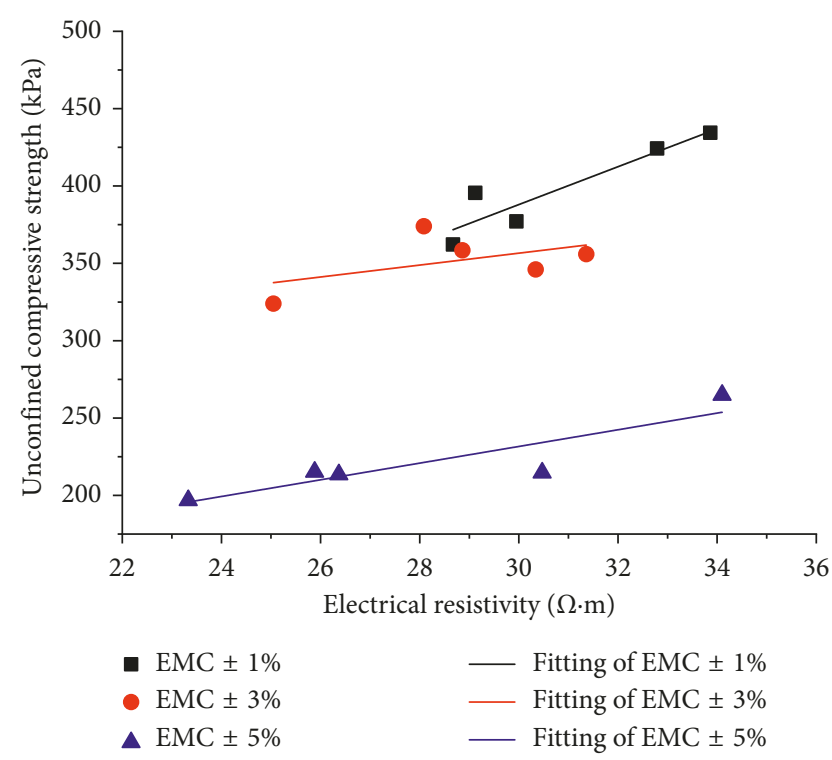

Figure 18: Relationship between electrical resistivity and unconfined compressive strength.

electrical resistivity of soil reveals an irreversible structure change in soil dominated by development of large pores. However, this process also promotes transfixion of more macrocracks and weakens the continuity of soil skeleton, leading to poor mechanical behaviour of soil. Thus, it can be suggested that electrical resistivity is suitable to indirectly reveal the mechanical behaviour of compacted unsaturated soil under cyclic wetting-drying in this study.

\section{Conclusion}

An investigation of the effects of wetting-drying cycles on electrical resistivity and unconfined compressive strength of unsaturated compacted subgrade soil has been carried out. The AC two-electrode method was adopted for measuring the electrical resistivity of soil. The influences of number and cyclic amplitude of wetting-drying were both investigated in this study. From this study, it can be concluded as follows:

(1) The electrical resistivity of soil decreases with increasing moisture content at constant dry density and increasing dry density at constant moisture content.

(2) The soil strength reduces with larger number of wetting-drying, and after 3-4 cycles, the soil strength tends to be constant. Larger cyclic amplitude of wetting-drying results in more surface cracks after failure and significant decline of soil strength.

(3) The electrical resistivity shows a fluctuant downward trend with increasing number of wetting-drying cycles. Moreover, higher fluctuation of electrical resistivity is caused for specimens subjected to larger cyclic amplitude.

(4) The electrical resistivity decreases rapidly at the first three cycles and becomes a constant value after 3-4 cycles except the cyclic amplitude EMC $\pm 5 \%$. The increase of cyclic amplitude contributes to the reduction of electrical resistivity, especially after three wetting-drying cycles.

(5) The void ratio and degree of saturation of specimen show a hysteresis loop against electrical resistivity with increasing number of wetting-drying cycle. The hysteresis effect can be reduced when cyclic amplitude of wetting-drying decreases from EMC $\pm 5 \%$ to $\mathrm{EMC} \pm 1 \%$.

(6) The influence of porosity change on electrical resistivity is very limited for each end of wetting-drying cycle. The change of pore structure of soil during wetting-drying cycles has an effect on the electrical resistivity.

(7) The unconfined compressive strength shows a linear growth with the increasing electrical resistivity for a constant cyclic amplitude of wetting-drying cycles. Electrical resistivity is suitable to indirectly reveal the mechanical behaviour of compacted unsaturated soil under cyclic wetting-drying.

\section{Data Availability}

The data used to support the findings of this study are available from the corresponding author upon request.

\section{Conflicts of Interest}

The authors declare that they have no conflicts of interest.

\section{Acknowledgments}

The authors gratefully acknowledge the National Natural Science Foundation of China (nos. 51708190, 51678223, and 51678224), Hubei Provincial Science Foundation for Distinguished Young Scholars (no. 2018CFA063), Hubei Central Special Fund for Local Science and Technology Development (no. 2018ZYYD005), and National Program on Key Research Project of China (no. 2016YFC0502208).

\section{References}

[1] R. Chen and C. W. W. Ng, "Impact of wetting-drying cycles on hydro-mechanical behavior of an unsaturated compacted clay," Applied Clay Science, vol. 86, pp. 38-46, 2013.

[2] J. Zhang, Q. Jiang, Y. Zhang, L. Dai, and H. Wu, "Nondestructive measurement of water content and moisture migration of unsaturated red clays in south China," Advances in Materials Science and Engineering, vol. 2015, Article ID 542538, 7 pages, 2015.

[3] C. Farulla, A. Ferrari, and E. Romero, "Mechanical behaviour of compacted scaly clay during cyclic controlled-suction testing," in Experimental Unsaturated Soil Mechanics, T. Schanz, Ed., pp. 345-354, Springer, Berlin, Heidelberg, 2007.

[4] Y. Guney, D. Sari, M. Cetin, and M. Tuncan, "Impact of cyclic wetting-drying on swelling behavior of lime-stabilized soil," Building and Environment, vol. 42, no. 2, pp. 681-688, 2007.

[5] F. Akcanca and M. Aytekin, "Effect of wetting-drying cycles on swelling behavior of lime stabilized sand-bentonite 
mixtures," Environmental Earth Sciences, vol. 66, no. 1, pp. 67-74, 2012.

[6] A. R. Estabragh, B. Parsaei, and A. A. Javadi, "Laboratory investigation of the effect of cyclic wetting and drying on the behaviour of an expansive soil," Soils and Foundations, vol. 55, no. 2, pp. 304-314, 2015.

[7] C.-S. Tang, D.-Y. Wang, B. Shi, and J. Li, "Effect of wettingdrying cycles on profile mechanical behavior of soils with different initial conditions," Catena, vol. 139, pp. 105-116, 2016.

[8] R. Chen, T. Xu, W. Lei, Y. Zhao, and J. Qiao, "Impact of multiple drying-wetting cycles on shear behaviour of an unsaturated compacted clay," Environmental Earth Sciences, vol. 77, p. $683,2018$.

[9] J.-M. Fleureau, S. Kheirbek-Saoud, R. Soemitro, and S. Taibi, "Behavior of clayey soils on drying-wetting paths," Canadian Geotechnical Journal, vol. 30, no. 2, pp. 287-296, 1993.

[10] L. Kong, H. M. Sayem, and H. Tian, "Influence of dryingwetting cycles on soil-water characteristic curve of undisturbed granite residual soils and microstructure mechanism by nuclear magnetic resonance (NMR) spin-spin relaxation time (T2) relaxometry," Canadian Geotechnical Journal, vol. 55, no. 2, pp. 208-216, 2018.

[11] G. Bodner, P. Scholl, and H.-P. Kaul, "Field quantification of wetting-drying cycles to predict temporal changes of soil pore size distribution," Soil and Tillage Research, vol. 133, pp. 1-9, 2013.

[12] L. F. Pires, L. V. Prandel, and S. C. Saab, "The effect of wetting and drying cycles on soil chemical composition and their impact on bulk density evaluation: an analysis by using XCOM data and gamma-ray computed tomography," Geoderma, vol. 213, pp. 512-520, 2014.

[13] L. Pires, O. Bacchi, and K. Reichardt, "Assessment of soil structure repair due to wetting and drying cycles through $2 \mathrm{D}$ tomographic image analysis," Soil and Tillage Research, vol. 94, no. 2, pp. 537-545, 2007.

[14] Z. Lu and J. M. Sabatier, "Effects of soil water potential and moisture content on sound speed," Soil Science Society of America Journal, vol. 73, no. 5, pp. 1614-1625, 2009.

[15] C.-S. Tang, Y.-J. Cui, B. Shi, A.-M. Tang, and C. Liu, "Desiccation and cracking behaviour of clay layer from slurry state under wetting-drying cycles," Geoderma, vol. 166, no. 1, pp. 111-118, 2011.

[16] H. Tian, C. Wei, H. Wei, R. Yan, and P. Chen, "An NMRbased analysis of soil-water characteristics," Applied Magnetic Resonance, vol. 45, no. 1, pp. 49-61, 2014.

[17] K. Sudha, M. Israil, S. Mittal, and J. Rai, "Soil characterization using electrical resistivity tomography and geotechnical investigations," Journal of Applied Geophysics, vol. 67, no. 1, pp. 74-79, 2009.

[18] J. H. Kim, H.-K. Yoon, and J.-S. Lee, "Void ratio estimation of soft soils using electrical resistivity cone probe," Journal of Geotechnical and Geoenvironmental Engineering, vol. 137, no. 1, pp. 86-93, 2011.

[19] L. D. Suits, T. C. Sheahan, J. A. Muñoz-Castelblanco et al., "The influence of changes in water content on the electrical resistivity of a natural unsaturated loess," Geotechnical Testing Journal, vol. 35, no. 1, pp. 11-17, 2012.

[20] Z. Cao, L. Xiang, E. Peng, and K. Li, "Experimental study on electrical resistivity of cement-stabilized lead-contaminated soils," Advances in Civil Engineering, vol. 2018, Article ID 4628784, 11 pages, 2018.

[21] C.-S. Tang, D.-Y. Wang, C. Zhu, Q.-Y. Zhou, S.-K. Xu, and B. Shi, "Characterizing drying-induced clayey soil desiccation cracking process using electrical resistivity method," Applied Clay Science, vol. 152, pp. 101-112, 2018.

[22] S. P. Friedman, "Soil properties influencing apparent electrical conductivity: a review," Computers and Electronics in Agriculture, vol. 46, no. 1-3, pp. 45-70, 2005.

[23] G. Kibria and M. S. Hossain, "Investigation of geotechnical parameters affecting electrical resistivity of compacted clays," Journal of Geotechnical and Geoenvironmental Engineering, vol. 138, no. 12, pp. 1520-1529, 2012.

[24] Z. Lu, X. Wu, Z. Hu, S. Xian, and R. Fang, "Electric resistance tests on compacted clay material under dynamic load coupled with dry-wet cycling," Advances in Materials Science and Engineering, vol. 2018, Article ID 5387540, 6 pages, 2018.

[25] W. Bai, L. Kong, and A. Guo, "Effects of physical properties on electrical conductivity of compacted lateritic soil," Journal of Rock Mechanics and Geotechnical Engineering, vol. 5, no. 5, pp. 406-411, 2013.

[26] C. Huang, P. Hughes, D. Toll et al., "Electrical resistivity and mechanical behaviour of unsaturated soil under multiple cycles of drying and wetting," in Proceedings of the 7th International Conference on Unsaturated Soils, Hong Kong, China, Augest 2018.

[27] Z. Hu and Y. Z. Cheng, "Effectiveness of non-suction controlled method of wetting-drying cycles for unsaturated compacted loess material," Key Engineering Materials, vol. 748, pp. 346-349, 2017.

[28] H. Von Quintus and B. Killingsworth, Analyses Relating to Pavement Material Characterizations and Their Effects on Pavement Performance (Publication no. FHWA-RD-97-085), Federal Highway Administration, Mclean, VA, USA, 1998.

[29] H. Lv, Z. Zeng, Y. Zhao, and H. Lu, "Experimental studies of strength of expansive soil in drying and wetting cycles," Rock and Soil Mechanics, vol. 30, no. 12, pp. 3797-3802, 2009.

[30] F. Yazdandoust and S. S. Yasrobi, "Effect of cyclic wetting and drying on swelling behavior of polymer-stabilized expansive clays," Applied Clay Science, vol. 50, no. 4, pp. 461-468, 2010.

[31] W. J. McCarter, "The electrical resistivity characteristics of compacted clays," Géotechnique, vol. 34, no. 2, pp. 263-267, 1984.

[32] V. A. Rinaldi and G. A. Cuestas, "Ohmic conductivity of a compacted silty clay," Journal of Geotechnical and Geoenvironmental Engineering, vol. 128, no. 10, pp. 824-835, 2002.

[33] N. Lu and W. J. Likos, Unsaturated Soil Mechanics, John Wiley \& Sons. Inc., New York, USA, 2004.

[34] J. Lemaitre and J. Dufailly, "Damage measurements," Engineering Fracture Mechanics, vol. 28, no. 5-6, pp. 643-661, 1987.

[35] J. D. Rhoades, N. A. Manteghi, P. J. Shouse, and W. J. Alves, "Soil electrical conductivity and soil salinity: new formulations and calibrations," Soil Science Society of America Journal, vol. 53, no. 2, pp. 433-439, 1989.

[36] M. A. Mojid, D. A. Rose, and G. C. L. Wyseure, "A model incorporating the diffuse double layer to predict the electrical conductivity of bulk soil," European Journal of Soil Science, vol. 58, no. 3, pp. 560-572, 2007.

[37] R. Ma, C. Cai, Z. Li et al., "Evaluation of soil aggregate microstructure and stability under wetting and drying cycles in two Ultisols using synchrotron-based X-ray micro-computed tomography," Soil and Tillage Research, vol. 149, pp. 1-11, 2015. 


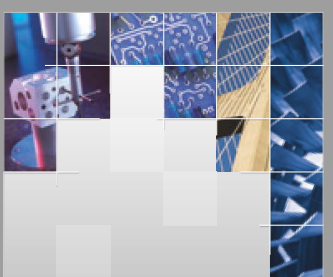

\section{Enfincering}
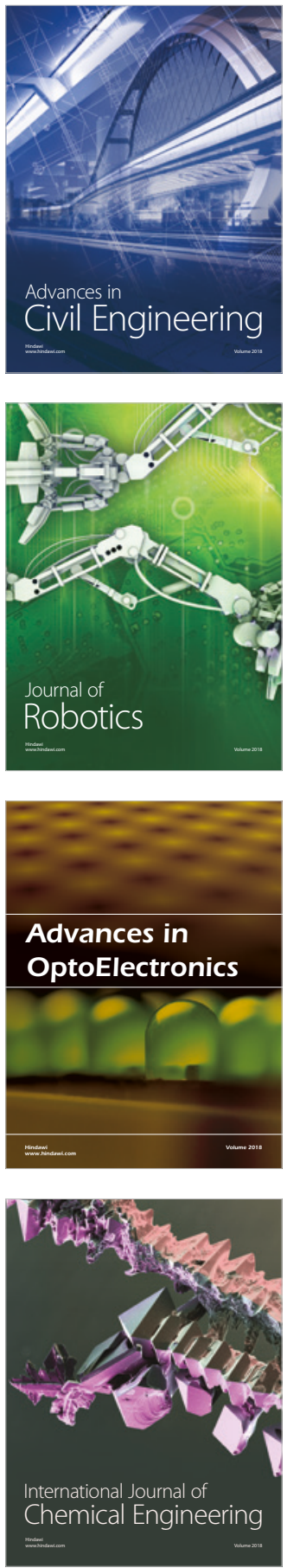

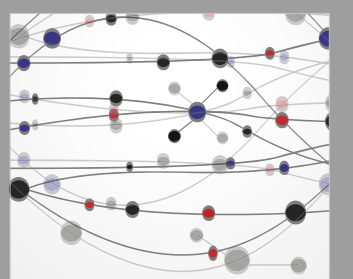

\section{Rotating \\ Machinery}

The Scientific World Journal

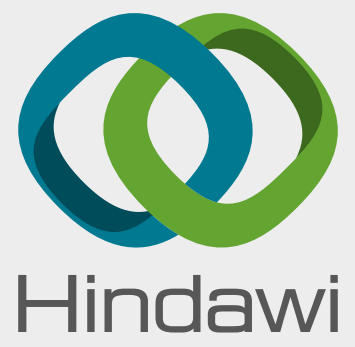

Submit your manuscripts at

www.hindawi.com
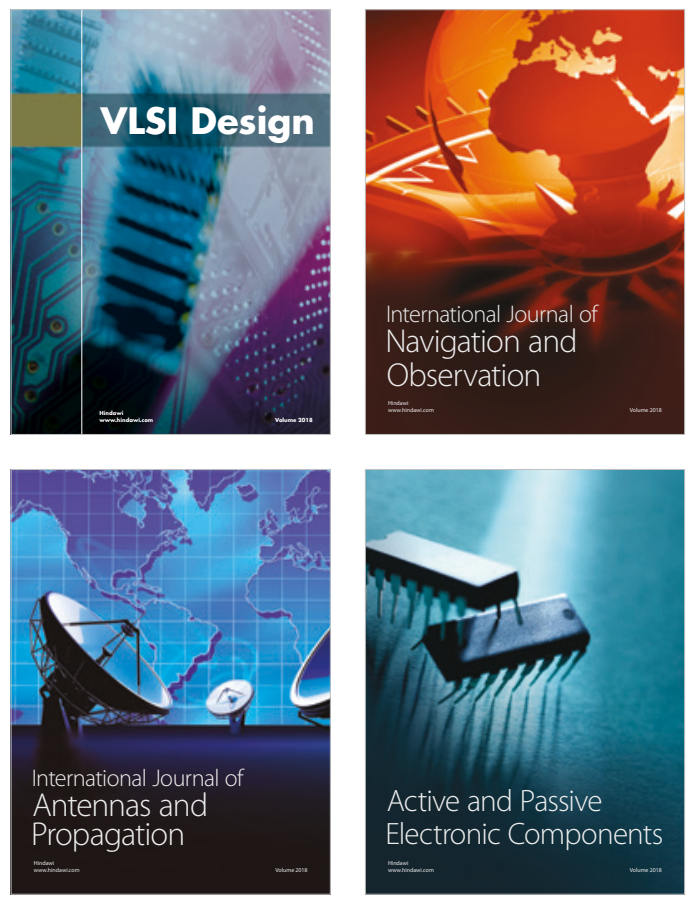
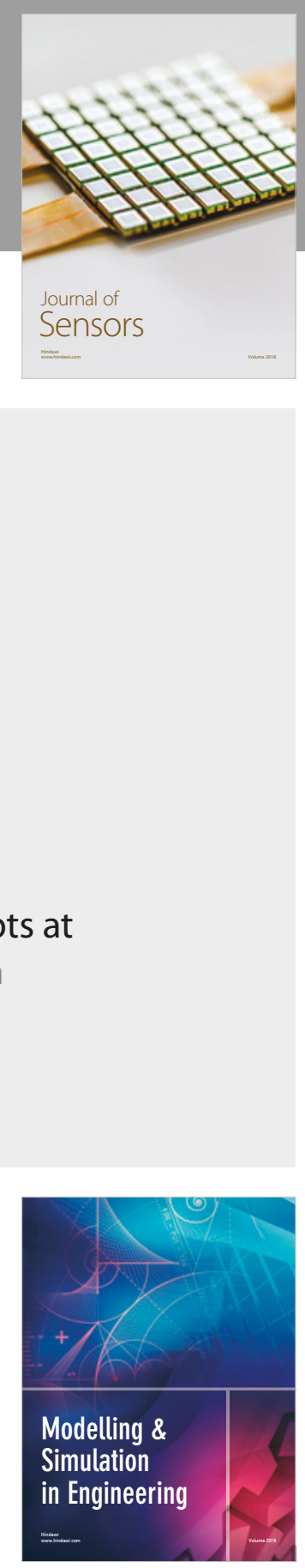

\section{Advances \\ Multimedia}
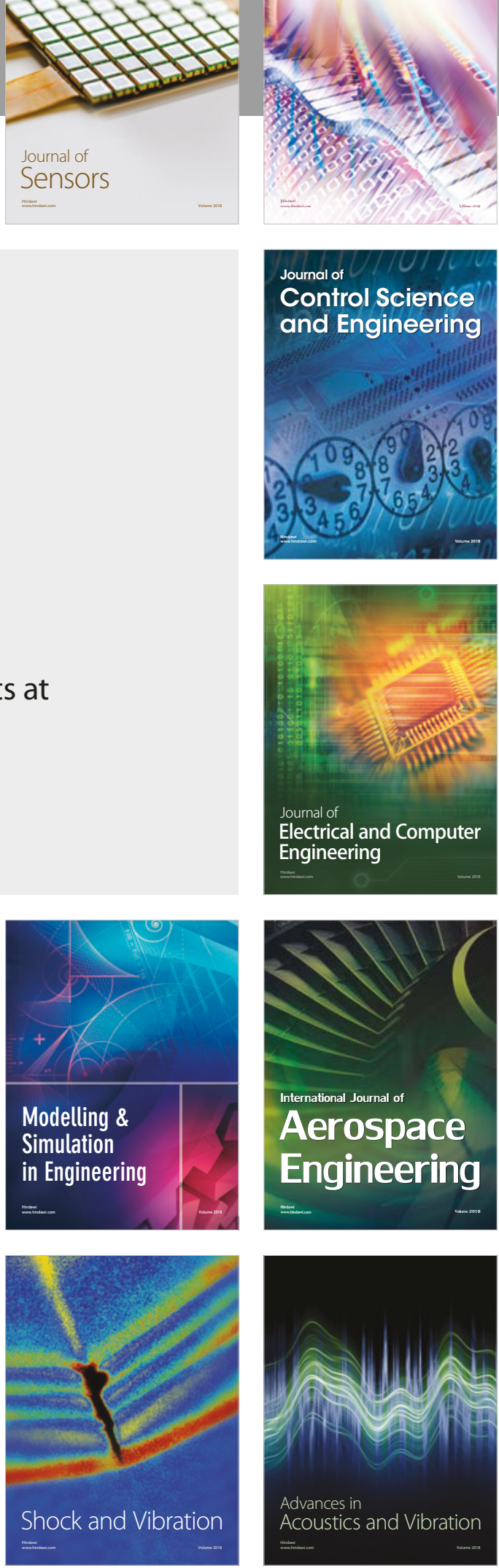